\title{
Carotid Stiffness: A Novel Cerebrovascular Disease Risk Factor
}

\author{
Thomas T. van Sloten Coen D.A. Stehouwer \\ Department of Internal Medicine and the Cardiovascular Research Institute Maastricht, \\ Maastricht University Medical Centre, Maastricht, The Netherlands
}

\section{Key Words}

Carotid stiffness $\cdot$ Cerebrovascular disease

\begin{abstract}
Carotid stiffening is considered an important element in the pathogenesis of cerebrovascular diseases. These include stroke as well as vascular dementia and depression. However, results of individual studies evaluating the association between carotid stiffening and incident stroke have been inconsistent. Therefore, we have conducted a systematic review and meta-analysis, showing that carotid stiffening is associated with incident stroke independently of cardiovascular risk factors and aortic stiffness. In addition, carotid stiffening improved stroke risk prediction beyond the Framingham stroke risk factors and aortic stiffness. Other studies have shown that carotid stiffening is associated with a higher incidence of vascular dementia and depressive symptoms. This suggests that carotid stiffness is a potential separate target for prevention strategies of cerebrovascular disease.

(c) 2016 The Author(s) Published by S. Karger AG, Basel
\end{abstract}

Cerebrovascular disease is one of the leading causes of disability and mortality worldwide [1-3]. The global burden of cerebrovascular diseases, including stroke as well as vascular dementia and depression, has greatly increased in the last decades and will continue to increase in the coming years [3]. Therefore, effective prevention strategies need to be developed, which require a better understanding of cerebrovascular disease risk factors.

Stiffening of the carotid artery (or of other elastic arteries for which the carotid artery may serve as a proxy) may lead to cerebrovascular disease via multiple mechanisms (fig. 1). Increased stiffness of the carotid artery leads to a higher pulsatile pressure and flow load on the brain [4-6]. This increased load can penetrate distally into the cerebral microcirculation and may directly cause cerebral ischemia and hemorrhage. The brain may be particularly 
van Sloten and Stehouwer: Carotid Stiffness: A Novel Cerebrovascular Disease Risk Factor

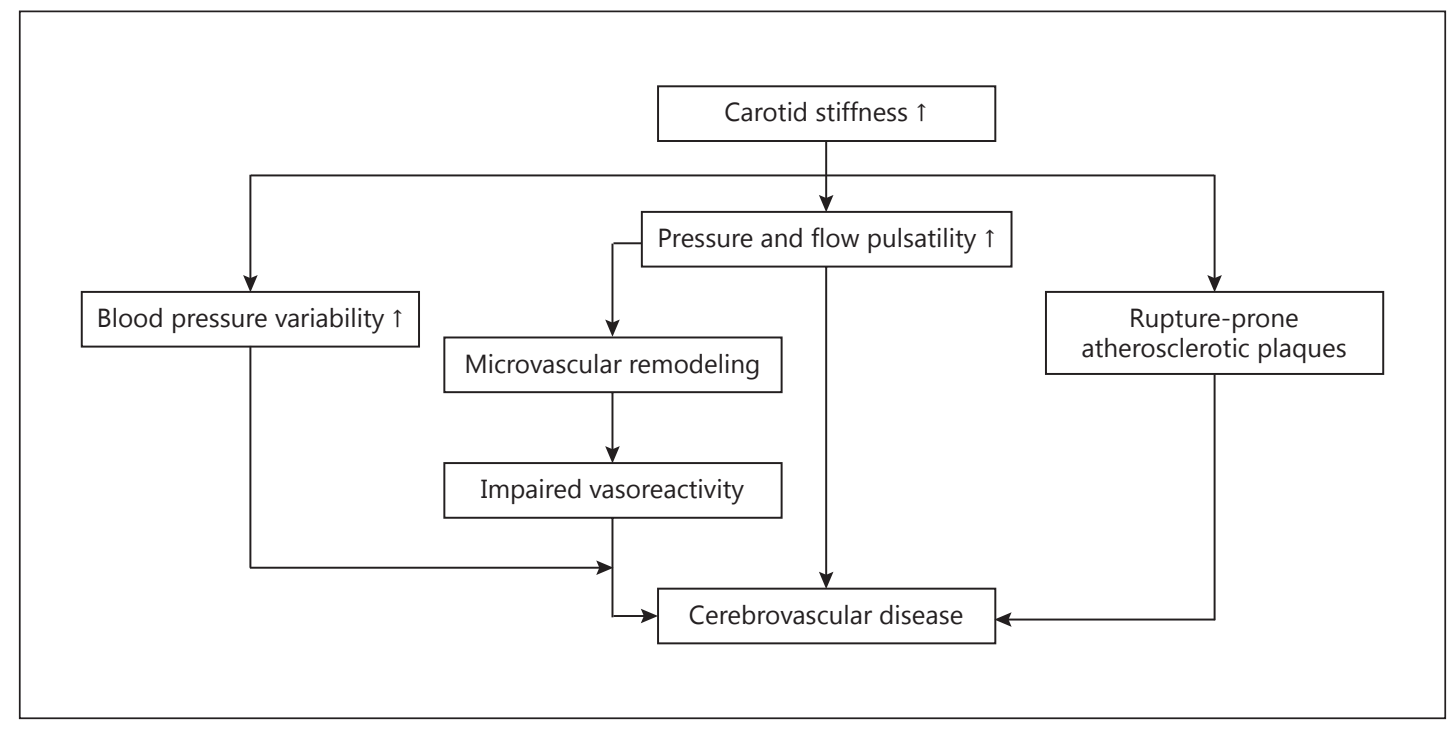

Fig. 1. Potential pathways by which arterial stiffening can lead to cerebrovascular disease.

prone to the detrimental effects of an increased load, because its microcirculation is characterized by low impedance, allowing the pulsatile load to penetrate deeply into its microvascular bed $[4,5]$. Also, the increased pulsatile load may induce a hypertrophic remodeling response and rarefaction of small cerebral arteries, which initially serves to limit the penetration of the pulsatile load into the microcirculatory system by raising vascular resistance [6]. However, this protective response may ultimately become unfavorable, leading to impaired vasoreactivity, hypoperfusion and chronic ischemia. In addition, increased stiffness of elastic arteries may cause excessive blood pressure variability $[7,8]$, which may further sensitize high-flow organs to the harmful effects of impaired microvascular vasoreactivity [4]. Finally, carotid artery stiffening may lead to cerebrovascular disease through local development of rupture-prone atherosclerotic plaques [6,9].

We have performed a systematic review and an aggregate and individual participant data meta-analysis [10] to evaluate the association between carotid stiffening and incident stroke. The aggregate data meta-analysis, which included ten studies ( $\mathrm{n}=22,472$ ), showed that greater carotid stiffness was associated with a higher stroke incidence. In addition, carotid stiffening was associated with incident total cardiovascular events and cardiovascular and all-cause mortality, but not with coronary heart disease events. An additional individual participant data meta-analysis, which included four studies $(n=4,540)$, showed that additional adjustment for aortic stiffness, as measured by carotid-femoral pulse wave velocity (cfPWV), did not materially change these associations (table 1). Furthermore, carotid stiffening improved stroke risk prediction beyond the Framingham stroke risk factors and cfPWV, as indicated by a statistically significant integrated discrimination improvement and continuous net reclassification improvement (table 1).

This study thereby identifies carotid stiffening as a potential separate target for stroke risk-lowering therapy. Cardiovascular disease risk factors have different impacts on stiffening of elastic versus muscular arteries $[11,12]$. This may be attributed to the marked differences in the architecture of these arteries and suggests that stiffening of elastic arteries may be specifically targeted. Currently, however, no effective clinical therapy is available that specifically targets stiffening of elastic arteries. 
van Sloten and Stehouwer: Carotid Stiffness: A Novel Cerebrovascular Disease Risk Factor

Table 1. Results of individual participant data meta-analysis [10]

\begin{tabular}{|c|c|}
\hline Models & $\begin{array}{l}\text { Carotid DC (per } 1 \text { lower SD) as the determinant and } \\
\text { incident stroke as the outcome }{ }^{1}\end{array}$ \\
\hline $\begin{array}{l}\text { Cox regression analysis } \\
\quad \text { Model } 1^{2} \\
\text { Model } 1^{2}+\text { cfPWV }\end{array}$ & $\begin{array}{l}\text { Hazard ratio (95\% confidence interval) } \\
1.24(1.05 ; 1.47) \\
1.24(1.05 ; 1.46)\end{array}$ \\
\hline $\begin{array}{l}\text { Risk improvement analysis }{ }^{3} \\
\text { IDI, \% point } \\
\text { Continuous NRI, \% }\end{array}$ & $\begin{array}{l}\text { Effect estimate }(95 \% \text { confidence interval) } \\
0.4(0.1 ; 0.6) \\
18.6(5.8 ; 31.3)\end{array}$ \\
\hline \multicolumn{2}{|c|}{$\begin{array}{l}\text { Association between carotid stiffness and incident stroke: additional adjustments for cfPWV and analysis } \\
\text { of risk improvement. The model was extended by the carotid distensibility coefficient (DC). SD = Standard } \\
\text { deviation; IDI = integrated discrimination improvement; NRI = net reclassification index. } \\
{ }^{1} \text { Number of participants for this analysis: } \mathrm{n}=4,075 \text {, with } 351 \text { events and } 47,881 \text { person-years of follow-up. } \\
{ }^{2} \text { Model 1: results adjusted for age, sex, mean arterial pressure, heart rate, body mass index, smoking } \\
\text { habits, diabetes, triglycerides, total/high-density lipoprotein cholesterol ratio, prior cardiovascular disease, } \\
\text { and the use of lipid-modifying and antihypertensive medication. } \\
3 \text { The baseline model for risk improvement analysis included the Framingham stroke risk score factors } \\
\text { and cfPWV. }\end{array}$} \\
\hline
\end{tabular}

In addition, the study provides proof of principle that carotid stiffening can have additional value as a risk predictor of stroke. However, the improvement in stroke risk prediction by carotid stiffening was modest. Furthermore, the study included high-risk populations (i.e. older individuals and/or individuals with diabetes or chronic kidney disease). In these populations, such a modest improvement may not be clinically relevant [13]. Nevertheless, the study provides a framework for investigating whether assessment of carotid stiffness can improve stroke risk prediction in younger individuals and in those at intermediate risk for stroke, in whom improvement in risk prediction may be of greater importance [14].

Recent studies have suggested that carotid stiffening may also lead to brain diseases other than stroke, including dementia and late-life depression, and that these associations are mediated by cerebrovascular damage. Cerebrovascular damage plays an important role in the pathogenesis of cognitive impairment, including dementia [15]. In addition, it has been suggested [16-18] that cerebral microvascular damage leads to depression via disruption of deep and frontal brain structures or their connecting pathways involved in mood regulation, in particular in older individuals (vascular depression hypothesis). Systematic reviews and meta-analyses $[19,20]$ have shown an association between arterial stiffening (including carotid stiffening) and cognitive impairment. In addition, The Rotterdam Study [21] has shown an association between increased carotid stiffness and a higher incidence of depressive symptoms. Furthermore, the AGES-Reykjavik Study [22,23] showed that the associations of arterial stiffening with cognitive impairment and depressive symptoms are in part mediated by cerebral small vessel disease.

In conclusion, greater carotid stiffness is associated with a higher incidence of stroke, and carotid stiffening modestly improved risk prediction of stroke beyond the Framingham stroke risk score factors and cfPWV. Furthermore, carotid stiffening may lead to brain diseases other than stroke, including vascular dementia and depression, and these associations may be mediated by cerebrovascular damage. This identifies carotid stiffening as a potential separate target for prevention strategies of cerebrovascular disease. 
van Sloten and Stehouwer: Carotid Stiffness: A Novel Cerebrovascular Disease Risk Factor

\section{Disclosure Statement}

The authors declare no conflicts of interest.

\section{References}

1 Feigin VL, Forouzanfar MH, Krishnamurthi R, et al: Global and regional burden of stroke during 1990-2010: findings from the Global Burden of Disease Study 2010. Lancet 2014;383:245-254.

2 Global Burden of Disease Study 2013 Collaborators: Global, regional, and national incidence, prevalence, and years lived with disability for 301 acute and chronic diseases and injuries in 188 countries, 1990-2013: a systematic analysis for the Global Burden of Disease Study 2013. Lancet 2015;386:743-800.

3 Ovbiagele B, Goldstein LB, Higashida RT, et al: Forecasting the future of stroke in the United States: a policy statement from the American Heart Association and American Stroke Association. Stroke 2013;44:23612375.

4 Mitchell GF: Effects of central arterial aging on the structure and function of the peripheral vasculature: implications for end-organ damage. J Appl Physiol 2008;105:1652-1660.

5 O'Rourke MF, Safar ME: Relationship between aortic stiffening and microvascular disease in brain and kidney: cause and logic of therapy. Hypertension 2005;46:200-204.

6 Tzourio C, Laurent S, Debette S: Is hypertension associated with an accelerated aging of the brain? Hypertension 2014;63:894-903.

7 Rothwell PM: Limitations of the usual blood-pressure hypothesis and importance of variability, instability, and episodic hypertension. Lancet 2010;375:938-948.

8 Schillaci G, Bilo G, Pucci G, et al: Relationship between short-term blood pressure variability and large-artery stiffness in human hypertension: findings from 2 large databases. Hypertension 2012;60:369-377.

9 Selwaness M, van den Bouwhuijsen Q, Mattace-Raso FU, et al: Arterial stiffness is associated with carotid intraplaque hemorrhage in the general population: the Rotterdam study. Arterioscler Thromb Vasc Biol 2014;34: 927-932.

10 van Sloten TT, Sedaghat S, Laurent S, et al: Carotid stiffness is associated with incident stroke: a systematic review and individual participant data meta-analysis. J Am Coll Cardiol 2015;66:2116-2125.

11 Paini A, Boutouyrie P, Calvet D, Tropeano AI, Laloux B, Laurent S: Carotid and aortic stiffness: determinants of discrepancies. Hypertension 2006;47:371-376.

12 Stehouwer CD, Henry RM, Ferreira I: Arterial stiffness in diabetes and the metabolic syndrome: a pathway to cardiovascular disease. Diabetologia 2008;51:527-539.

13 Pencina MJ, D'Agostino RB, Pencina KM, Janssens AC, Greenland P: Interpreting incremental value of markers added to risk prediction models. Am J Epidemiol 2012;176:473-481.

14 Lloyd-Jones DM: Cardiovascular risk prediction: basic concepts, current status, and future directions. Circulation 2010;121:1768-1777.

15 Gorelick PB, Scuteri A, Black SE, et al: Vascular contributions to cognitive impairment and dementia: a statement for healthcare professionals from the American Heart Association/American Stroke Association. Stroke 2011;42:2672-2713.

16 Krishnan KR, Hays JC, Blazer DG: MRI-defined vascular depression. Am J Psychiatry 1997;154:497-501.

17 Alexopoulos GS, Meyers BS, Young RC, Campbell S, Silbersweig D, Charlson M: 'Vascular depression' hypothesis. Arch Gen Psychiatry 1997;54:915-922.

18 van Sloten TT, Sigurdsson S, van Buchem MA, et al: Cerebral small vessel disease and association with higher incidence of depressive symptoms in a general elderly population: the AGES-Reykjavik Study. Am J Psychiatry 2015;172:570-578.

19 van Sloten TT, Protogerou AD, Henry RM, Schram MT, Launer LJ, Stehouwer CD: Association between arterial stiffness, cerebral small vessel disease and cognitive impairment: a systematic review and meta-analysis. Neurosci Biobehav Rev 2015;53:121-130.

20 Singer J, Trollor JN, Baune BT, Sachdev PS, Smith E: Arterial stiffness, the brain and cognition: a systematic review. Ageing Res Rev 2014;15:16-27.

21 Tiemeier H, Breteler MM, van Popele NM, Hofman A, Witteman IC: Late-life depression is associated with arterial stiffness: a population-based study. J Am Geriatr Soc 2003;51:1105-1110.

22 van Sloten TT, Mitchell GF, Sigurdsson S, et al: Associations between arterial stiffness, depressive symptoms and cerebral small vessel disease: cross-sectional findings from the AGES-Reykjavik Study. J Psychiatry Neurosci 2015;41:140334.

23 Cooper LL, Woodard T, Sigurdsson S, et al: Cerebrovascular damage mediates relations between aortic stiffness and memory. Hypertension 2016;67:176-182. 